\title{
EARLY IMPAIRMENT OF COGNITIVE FUNCTIONS IN PARKINSON'S DISEASE
}

\author{
Florindo Stella ${ }^{1,2}$, Lilian T. B. Gobbi², Sebastião Gobbi², \\ Merlyn M. Oliani³, Kátia Tanaka³, Frederico Pieruccini-Faria ${ }^{3}$
}

\begin{abstract}
Background: Impairment in non-motor functions such as disturbances of some executive functions are also common events in Parkinson's disease patients. Objective: To verify the performance of Parkinson's disease patients in activities requiring visuoconstructive and visuospatial skills. Method: Thirty elderly patients with mild or moderate stages of Parkinson's disease were studied. The assessment of the clinical condition was based on the unified Parkinson's disease rating scale (56.28; SD=33.48), Hoehn and Yahr (2.2; SD=0.83), Schwab and England (78.93\%), clock drawing test (7.36; SD=2.51), and mini-mental state examination (26.48; SD=10.11). Pearson's correlation and stepwise multiple regression were used for statistical analyses. Results: The patients presented deterioration in visuospatial and visuoconstructive skills. Conclusion: The clock drawing test proved to be a useful predictive tool for identifying early cognitive impairment in these individuals.
\end{abstract}

KEY WORDS: Parkinson's disease, cognition disorders, neuropsychological tests.

\begin{abstract}
Comprometimento precoce das funções cognitivas na doença de Parkinson
RESUMO - Contexto: Comprometimento em funções não-motoras como perturbações em algumas funções executivas são também eventos comuns em pacientes com doença de Parkinson. Objetivo: Verificar as performances de pacientes com doença de Parkinson em atividades que requerem habilidades visuo-construtivas e visuo-espaciais. Método: Pacientes idosos $(n=30)$ nos estágios leve ou moderado da doença de Parkinson foram estudados. O diagnóstico da condição clínica foi realizado por meio de: unified Parkinson's disease rating scale $(56,28 ; S D=33,48)$, Hoehn e Yahr $(2,2 ; S D=0,83)$, Schwab e England $(78,93 \%)$, teste do desenho do relógio (7,36; $S D=2,51)$, e mini-exame do estado mental $(26,48 ; S D=10,11)$. A correlação de Pearson e a análise de regressão múltipla foram empregadas na análise estatística. Resultados: Os pacientes apresentaram deterioração nas habilidades vísuo-espaciais e visuoconstrutivas. Conclusão: O teste do desenho do relógio provou ser uma ferramenta útil e preditiva para identificar o comprometimento cognitivo precoce nesses indivíduos.
\end{abstract}

PALAVRAS-CHAVE: doença de Parkinson, desordens cognitivas, testes neuropsicológicos.

Besides the classical symptoms of Parkinson's disease (PD) such as rest tremor, rigidity, bradykinesia and postural instability and its high prevalence in Brazilian clinical settings ${ }^{1}$ impaired non-motor functions such as cognitive disorders are also common events $^{2}$. At the disease onset, $24 \%$ of patients present cognitive decay, especially memory disorders and disturbances of some executive functions such as impaired selective attention, thinking flexibility, and planning difficulty ${ }^{3}$. In dementia, the patient with PD also reveals deterioration of declarative memory (but with relative preserved recognition), visuoconstructive skills, and nominating ability ${ }^{4}$. These distur- bances depend on mostly frontal-striatum connections ${ }^{5}$ and involve other areas of the brain such as the parietal regions and subcortical structures ${ }^{6}$.

With respect to the non-motor symptoms of moderate and mild PD, we proposed the following hypotheses in the present study: A) patients in the initial stages of PD, and without clinical dementia, may present early impairment of several cognitive functions, such as visuoconstructive and visuospatial skills; and $\mathrm{B}$ ) The clock drawing test (CDT), a simple and easily applicable tool, helps in identifying these early alterations.

This study aimed to identify early cognitive im-

\footnotetext{
${ }^{1}$ Professor of Clinic in Neuropsychiatry and Mental Health for Elderly, UNICAMP - State University of Campinas, Campinas SP, Brazil; ${ }^{2}$ Professor, UNESP - São Paulo State University at Rio Claro SP, Brazil; ${ }^{3}$ Graduate Student, UNESP - São Paulo State University at Rio Claro SP, Brazil.
}

Received 24 August 2006, received in final form 12 December 2006. Accepted 14 February 2007. 
pairment in tasks requiring visuoconstructive and visuospatial skills in patients with mild and moderate idiopathic PD, and to verify if the clock drawing test and mini-mental state examination (MMSE) contribute towards the early detection of these impairments.

\section{METHOD}

Subjects - The sample was composed of a consecutive series of 30 patients, men and women, aged 53 to 80 years, from of a physical activity program for PD patients. No limitations were previously established with respect to the age of the subjects; the upper and lower age limits were a result of the referrals of the subjects to the physical activity program by their respective clinicians. The program is coordinated by the physical activity and aging laboratory and the posture and locomotion study laboratory, at UNESP (State University of São Paulo), Rio Claro, Brazil. The participants were classified in clinical stages one to three on the Hoehn and Yahr scale 7 . Patients in these stages were selected due to the fact that those in more advanced stages would not meet the requirements for the motor activities programmed. All the patients were in the "ON" phase of idiopathic PD treatment with regular anti-Parkinsonian drugs in monotherapy (e.g. pramipexol or selegiline) or polytherapy (levadopa plus other drugs such as benserazide, pramipexol or entacapone). The present study was an open, cross-sectional study to investigate the cognitive function of the patients; thus, due to the type of research and the aims, a control group was not necessary. The inclusion criteria were: a) idiopathic PD diagnosed by a neurologist with clinical experience in this pathology; b) subjects classified from 1 to 3 Hoehn and Yahr staging; c) patients being treated for PD with regular prescriptions and in on phase of the medication; and d) patients without dementia. The exclusion criteria were: a) Parkinsonism secondary to stroke and other brain vascular events, brain trauma and other neurological or psychiatric conditions leading to motor disorders; b) patients in staging higher than 3 on the Hoehn and Yahr scale; c) patients in irregular treatment or in the off phase of the medication; and d) dementia or other mental neuropsychiatric conditions which could interfere with cognitive performance.

The Ethics Committee on Research, UNESP (São Paulo State University), at Rio Claro - Brazil, approved the study, and a free and informed consent was obtained from each participant.

Procedures - Trained professionals performed the clinical examination of patients, including a semi-structured interview, in order to investigate cognitive and motor condition. The unified Parkinson's disease rating scale (UPDRS) ${ }^{8}$ was applied for assessments of mental, functional and motor status. Also, the modified Hoehn and Yahr scale ${ }^{7}$ was used for characterizing and staging PD, identifying the presence of unilateral or bilateral disease, and responses to the postural test. The Schwab and England scale ${ }^{9}$ was used to estimate daily life activities. The clock drawing test ${ }^{10}$ and mini-mental state examination ${ }^{11,12}$ completed the neuropsychological assessment. While the MMSE is used for global cognitive screening, the CDT assesses different cognitive demands including executive functions (selective attention, planning a logical and sequential action, abstraction capacity, and performance monitoring), as well visuospatial organization, visuoconstructive praxis, psychomotor coordination and recent memory ${ }^{13}$. In this test, the individual was instructed to draw not only a complete reproduction of a clock figure, but also to insert its hands according to the hour specified by the researcher (according to Brazilian consensus, it was 02:45). To analyze the individuals' performance, the authors applied the Sunderland et al. ${ }^{10}$ recommendations about CDT, which are often chosen by Brazilian researchers ${ }^{14}$.

Data analysis - Statistical analysis of the results was done by means of parametric tests (Pearson's correlation and the stepwise multiple regression test). The Levine test revealed variance homogeneity of eight out of ten dependent variables selected for this study (Schwab and England and hemibody data did not present variance homogeneity). Therefore, parametric tests were performed. Correlations were used to predict cognitive impairment with scales that assessed mental, functional and motor symptoms. The significance level applied was $p \leq 0.05$, and SPSS 10.0 software was used for all the analyses.

\section{RESULTS}

The study sample consisted of 19 males and 11 females with mean age of 67.0 years $(S D=8.08)$ and mean educational level of 7.03 years $(S D=4.76)$. Clinical features included: disease onset at 59.42 years $(S D=10.53)$, and mean duration of PD 7.58 years $(S D=7.67)$. For the majority of patients, the symptoms began in the right hemibody, and at the onset of the disease, rest tremor was more frequent than rigidity. Most subjects were living with their families.

The patients presented a mean score of 2.2 on the modified Hoehn and Yahr $(S D=0.83)$ and 56.28 $(S D=33.48)$ on the UPDRS total, and their performance of daily life activities on Schwab and England was $78.93 \%$. The neuropsychological evaluation revealed a mean score of $26.48(S D=10.11)$ on the MMSE and 7.36 (SD=2.51) on the CDT. According to the parameters adopted in this study, these results suggest absence of dementia. Table 1 summarizes the data given from the scales.

Correlation of motor laterality with MMSE and $C D T$ - A mean score of $26.48(S D=10.11)$ in MMSE does not suggest dementia, according to Brazilian parameters adjusted for educational level. The multiple regression analysis revealed the MMSE to be a predictor of CDT result ( $p=0.043)$, although the deter- 
Table 1. Means, standard deviations (SD), and number of observations $(N)$ for each dependent variable.

\begin{tabular}{lccc}
\hline Variables & Mean & SD & $\mathrm{N}$ \\
\hline Hoehn and Yahr & 2.22 & 0.83 & 30 \\
Schwab and England (DLA) $^{\mathrm{a}}$ & 78.93 & 19.12 & 28 \\
MMSE $^{\mathrm{b}}$ & 26.48 & 10.11 & 27 \\
Clock drawing test $^{\text {U. }}$ & 7.36 & 2.51 & 25 \\
UPDRS $^{\mathrm{c}}$ mentation & 6.64 & 5.63 & 28 \\
UPDRS functional & 16.93 & 9.80 & 28 \\
UPDRS motor & 33.57 & 22.89 & 28 \\
UPDRS-total & 56.28 & 33.48 & 28 \\
\hline
\end{tabular}

${ }^{a}$ DLA, daily life activities; ${ }^{b} \mathrm{MMSE}$, mini-mental state examination; 'UPDRS, unified Parkinson's disease rating scale.

mination level was only $18 \%$. Nevertheless, the Pearson's correlation demonstrated a significant positive association between results of both tests $(p=0.025)$, as showed in Tables 2 and 3.

Laterality onset of motor symptoms occurred in the right hemibody among $60 \%$ of patients, in the left hemibody among $26.7 \%$, and was inconclusive in $13.3 \%$. Multiple regression analysis revealed significant positive correlation ( $p=0.003$ ) between educational levels and onset of motor symptoms in the right hemibody. These aspects (right hemibody and educational level) were predictive variables of $44.8 \%$ on MMSE performance.

CDT and UPDRS as predictors of daily life activities (DLA) - The Pearson's correlation revealed a significant negative correlation between CDT and UPDRS mentation $(p=0.04)$ and significant positive correlation of DLA (measured by Schwab and England) with CDT $(p=0.028)$. This association was confirmed by multiple regression analysis. In this case, lower CDT scores tend to be related to higher scores on the UPDRS functional ( $p=0.001$ ).

Moreover, multiple regression analysis showed that higher degree of motor difficulties and lower CDT scores explained $88.4 \%$ of the variation in performance of daily life activities as measured by the UPDRS functional. Both analyses (Pearson's correlation and multiple regression) indicated that patients with some impairment on CDT presented more difficulty in performing daily life activities, but without fulfilling criteria for dementia.

Tables 2 and 3 show the correlation among cognitive and clinical variables (Pearson's correlation), and association between predictive and dependent variables (multiple regression analysis), respectively.
Table 2. Pearson's correlation between cognitive and clinical variables.

\begin{tabular}{lcc}
\hline Variables & $r$ & $\mathrm{P}$ \\
\hline MMSE $^{\mathrm{a}}$ and CDT & & \\
MMSE and educational level & 0.45 & 0.025 \\
MMSE and hemibody & 0.39 & 0.047 \\
CDT and UPDRS ${ }^{\mathrm{c}}$ mentation & 0.55 & 0.003 \\
Schwab and England and CDT & -0.413 & 0.040 \\
\hline
\end{tabular}

${ }^{\mathrm{a} M M S E}$, mini-mental state examination; ${ }^{\mathrm{b}} \mathrm{CDT}$, clock drawing test; 'UPDRS, unified Parkinson's disease rating scale.

Table 3. Stepwise multiple regression analysis correlating dependent and predictive variables.

\begin{tabular}{llcc}
\hline Dependent variable & Predictor variable & $\mathrm{R}^{2}$ & $\mathrm{p}$ \\
\hline MMSE $^{\mathrm{a}}$ & Hemibody & 0.316 & 0.003 \\
& Years of schooling & 0.448 & \\
CDT $^{\mathrm{b}}$ & MMSE & 0.180 & 0.043 \\
UPDRS $^{\mathrm{c}}$ functional & UPDRS motor & 0.857 & 0.001 \\
& CDT & 0.884 & \\
\hline
\end{tabular}

${ }^{\mathrm{a} M M S E}$, mini-mental state examination; ${ }^{\mathrm{b}} \mathrm{CDT}$, clock drawing test; 'UPDRS, unified Parkinson's disease rating scale.

\section{DISCUSSION}

This study revealed mild but consistently impaired cognitive performance related to tasks requiring visuoconstructive activities and visuospatial organization such as CDT and pentagon reproduction from MMSE.

$C D T$ as a predictor of early cognitive impairment in $P D$ - Our results are in accordance with the findings of another study in patients with mild and moderate PD without diagnosis of dementia, but with early-impaired visuoconstructive praxis identified by figure drawing tests ${ }^{15}$. Early impairment on visuospatial organization in PD patients may represent a predicting factor for the later development of dementia ${ }^{16,17}$.

A positive correlation was verified between difficulty on CDT performance and more impaired daily life activities, as measured by the Schwab and England scale, even though these alterations did not constitute sufficient clinical criteria for diagnosis of dementia. These activities partly depend on visuospatial organization and visuoconstructive skill, besides being controlled by executive functions such as planning, selective attention, sequential action, abstraction capacity, and monitoring behavior. Moreover, reduced activity capacity also depends on the functional and motor condition of the individuals as indicated by correlations found between UPDRS 
functional and motor subscales (Table 3). The significant association between CDT and UPDRS functional (Table 3 ) suggests that the decay of the executive functions, identified by clock-drawing, could interfere with reduction in functional capacity in patients with PD.

Although CDT was originally planned to verify certain cortical functions in patients with Alzheimer's dementia $^{10}$, it also identifies several mental processes related to pre-frontal and subcortical mechanisms. These processes include behavior organization, mental flexibility, visuoconstructive performance, cognitive programming of psychomotor activity, and integration of visuospatial functions $s^{4,18,19}$.

With regard to mild and moderate stages of PD, patients in this study presented only a mild impairment in global cognitive functioning (MMSE scores) and on more specific cognitive demands (CDT scores) including executive functions (selective attention, planning a logical and sequential action, abstraction capacity, and performance monitoring) and visuospatial skills. Such findings are compatible with absence of dementia. The difficulty in reproducing the pentagon, as part of the MMSE and especially in designing in the CDT reveals impairment on visuoconstructive organization. Probably these difficulties are compatible with early impairment of executive functions required for designing mainly the clock, such as planning, logical sequential action, abstraction and monitoring performance in organizing visuospatial skills.

Left-side motor symptoms as predictors of early cognitive impairment in PD - Patients with onset of clinical motor symptoms in the left hemibody presented lower MMSE scores (Table 3 - hemibody and MMSE) when compared with patients with onset in the right hemibody. These results do not agree with other data from authors who particularly observed accentuated cognitive impairment related to onset of symptoms in the right hemibody ${ }^{20}$. Our data also differ from those from other studies that revealed more accentuated impairment in patients with symmetrical onset of motor symptoms ${ }^{2,21,22}$. Subjacent neurobiological mechanisms for a possible association between unilateral/bilateral PD and risk of dementia are still unknown.

Probably, cognitive disorders in PD are related to dysfunction of subcortical-cortical connections. Reduced dopaminergic activity affects striatal functioning and its connections to the prefrontal region, resulting in impaired cognitive functions such as vi- suospatial organization and visuoconstructive skills that are dependent on these pathways ${ }^{5,23,24}$. Cognitive activity in PD partially depends on dopaminergic loops linking striatum to the prefrontal region. Also, cholinergic pathways originating in the basal ganglia of Meynert with prefrontal cortex projections can have an influence ${ }^{5,24}$. When damaged, these pathways affect mainly executive cognitive functions, visuospatial organization and visuoconstructive skills $^{25-28}$. Moreover, $17 \%$ of patients with PD without dementia have a reduction in neurons from the basal nucleus of Meynert, and $50 \%$ present a reduction of acetylcholinetransferase, a precursor enzyme of acetylcholine ${ }^{29}$. This phenomenon has been associated with risk of dementia.

Since only a few patients were submitted to structural neuroimaging, especially magnetic resonance, one can argue that this is a limitation regarding the exclusion of diagnoses other than idiopathic Parkinson's disease. Although this is an actual matter of concern, this potential limitation was, hopefully, largely overcome by the fact that the diagnoses used in this study were achieved by clinical neurologists trained in diagnosing and treating PD, mainly based on anamnesis, semiological resources and laboratory exams that help identify movement disorders. Furthermore, around $90 \%$ of our sample presented unilateral onset of the parkinsonian symptoms and this can be also argued in favor of idiopathic PD.

In conclusion, patients in the mild and moderate stage of PD, without clinical diagnosis of dementia, presented mild cognitive impairment characterized by decay of visuospatial organization and visuoconstructive skills. These impairments were confirmed by means of the clock drawing test, and this finding suggests that this test can be a predictive tool of early cognitive disturbances in patients with PD without dementia.

\section{REFERENCES}

1. Cardoso F, Camargos S, Silva GA Jr. Etiology of parkinsonism in a Brazilian movement disorders clinic. Arq Neuropsiquiatr 1998;56:171-175.

2. Aarsland D, Andersen K, Larsen JP, Lolk A, Kragh-Sorensen P. Prevalence and characteristics of dementia in Parkinson disease: an 8-year prospective study. Arch Neurol 2003;60:387-392.

3. Muslimovic D, Post B, Speelman JD, Schmand B. Cognitive profile of patients with newly diagnosed Parkinson disease. Neurology 2005; 65:1239-1245.

4. Zgaljardic DJ, Borod JC, Foldi NS, Mattis P. A review of the cognitive and behavioral sequelae of Parkinson's disease: relationship to frontostriatal circuitry. Cogn Behav Neurol 2003;16:193-210.

5. Dujardin K, Defebvre L, Krystowiak P, Degreef JF, Destee A. Executive function differences in multiple system atrophy and Parkinson's disease. Parkinsonism Relat Disord 2003;9:205-211.

6. Vannini P, Almkvist O, Franck A, et al. Task demand mululations of visuospatial processing measured with functional magnetic resonance imaging. Neuroimage 2004;21:58-68. 
7. Hoehn MM, Yarh MD. Parkinsonism: onset, progression and mortality. Neurology 1967;17:427-442.

8. Fahn S, Elton R. Members of the UPDRS. Development Committee. The unified Parkinson's disease rating scale. In Fahn S, Marsden CD Calne DB, Goldstein M (Eds). Recent developments in Parkinson's disease 1987;2:153-164.

9. Schwab RS, England AC. Projection technique for evaluating surgery in Parkinson's disease. In Gillingham FJ, Donaldson ML (Eds). Third Symposium on Parkinson's Disease. Edinburgh: Livingstone 1969:152157.

10. Sunderland T, Hill JL, Mellow AM, et al. Clock drawing in Alzheimer's disease: a novel measure of dementia severity. J Am Geriatr Soc 1989;37:725-729.

11. Brucki SMD, Nitrini R, Caramelli P, Bertolucci PHF, Okamoto I. Sugestões para o uso do mini-exame do estado mental no Brasil. Arq Neuropsiquiatr 2003;61:777-781.

12. Folstein MF, Folstein SE, Mcghugh PR. Mini-Mental State: a practical method for grading the cognitive state of patients for the clinician. J Psychiatr Res 1975;12:189-198.

13. Royall DR, Cordes JA, Polk M. Clox: an executive clock drawing task. J Neurol Neurosurg Psyquiatry 1998;64:588-594.

14. Nitrini R, Caramelli P, Bottino CMC, et al. Diagnosis of Alzheimer's disease in Brazil: cognitive and functional evaluation. Recommendations of the Scientific Department of Cognitive Neurology and Aging of the Brazilian Academy of Neurology. Arq Neuropsiquiatr 2005;63:720-727.

15. Uc EY, Rizzo EY, Anderson SW, Qian S, Rodnitzky RL, Dawson JD. Visual dysfunction in Parkinson disease without dementia. Neurology 2005;65:1907-1913.

16. Janvin CC, Aarsland D, Larsen JP. Cognitive predictors of dementia in Parkinson's disease: a community-based, 4-year longitudinal study. J Geriatr Psychiatry Neurol 2005;18:149-154

17. Levy G, Jacobs DM, Tang MX, et al. Memory and executive function impairment predict dementia in Parkinson's disease. Mov Disord 2002;17:1221-1226.
18. Barbosa ER, Limongi JCP, Cummings JL. Parkinson's disease. Psychiatry Clin N Am 1997;20:769-790.

19. Sandyk R. Reversal of visuospatial deficit on the clock drawing test in Parkinson's disease by treatment with weak electromagnetic fields. Int J Neurosci 1995;82:255-268.

20. Grossman AB, Levin B, Katzen H, et al. Prospective study of lateralized tremor and its relationship to cognitive decline in Parkinson's disease. Ann Neurol 2001;50(Suppl):S22.

21. Papapetropoulos S, Gonzalez J, Lieberman A, Villar JM, Mash DC. Dementia in Parkinson's disease: a post-mortem study in a population of brain donors. Int J Geriatr Psychiatry 2005;20:418-422.

22. Viitanen M, Mortimer JA, Webster DD. Association between presenting motor symptoms and the risk of cognitive impairment in Parkinson's disease. J Neurol Neurosurg Psychiatry 1994;57:1203-1207.

23. Platz T, Mauritz KH. Human motor planning, motor programming, and use of new task-relevant information with different apraxic syndromes. Eur J Neurosci 1995;7:1536-1547.

24. Rippon GA, Marder KS. Dementia in Parkinson's disease. Adv Neurol 2005;96:95-113.

25. Carbon M, Ma Y, Barnes A, et al. Caudate nucleus: influence of dopaminergic input on sequence learning and brain activation in Parkinsonism. NeuroImage 2004;21:1384-1390.

26. Kuhl DE, Minoshima S, Fessler JA, et al. In vivo mapping of cholinergic terminals in normal aging, Alzheimer's disease, and Parkinson's disease. Ann Neurol 1996;40:399-410.

27. Shinotoh H, Namba H, Yamaguchi M, et al. Positron emission tomographic measurement of acetylcholinesterase activity reveals differential loss of ascending cholinergic systems in Parkinson's disease and progressive supranuclear palsy. Ann Neurol 1999;46:62-69.

28. Tekin S, Cummings JL. Frontal-subcortical neuronal circuits and clinical neuropsychiatry: an update. J Psychosom Res 2002;53:647-654.

29. Perry EK, Curtis M, Dick DJ, et al. Cholinergic correlates of cognitive impairment in Parkinson's disease: comparisons with Alzheimer's disease. J Neurol Neurosurg Psychiatry 1985;48:413-421. 